\title{
Analysis of 154 T4 Colorectal Cancer Patients with Peritoneal Carcinomatosis Treated by Surgery
}

\author{
Wei Chen ${ }^{1,2,3 *}$, Junwen Ye1,2,3*, Xiaoping Tan4*, Yan Zhang2,3,5, Jinglin Liang1,2,3\#, Meijin Huang 1,2,3\# \\ ${ }^{1}$ Department of Colorectal Surgery, The Sixth Affiliated Hospital, Sun Yat-sen University, Guangzhou, China \\ ${ }^{2}$ Guangdong Provincial Key Laboratory of Colorectal and Pelvic Floor Disease, The Sixth Affiliated Hospital of Sun Yat-sen \\ University, Guangzhou, China \\ ${ }^{3}$ Guangdong Research Institute of Gastroenterology, The Sixth Affiliated Hospital of Sun Yat-sen University, \\ Guangzhou, China \\ ${ }^{4}$ Department of Emergency, The Second Affiliated Hospital of Guangzhou Medical University, Guangzhou, China \\ ${ }^{5}$ Department of Medicine Oncology, The Sixth Affiliated Hospital, Sun Yat-sen University, Guangzhou, China

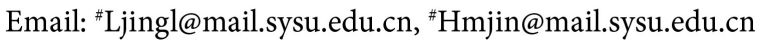

How to cite this paper: Chen, W., Ye, J.W., Tan, X.P., Zhang, Y., Liang, J.L. and Huang, M.J. (2021) Analysis of 154 T4 Colorectal Cancer Patients with Peritoneal Carcinomatosis Treated by Surgery. International Journal of Clinical Medicine, 12, 6170.

https://doi.org/10.4236/ijcm.2021.122008

Received: September 15, 2020

Accepted: February 21, 2021

Published: February 24, 2021

Copyright $\odot 2021$ by author(s) and Scientific Research Publishing Inc. This work is licensed under the Creative Commons Attribution International License (CC BY 4.0).

http://creativecommons.org/licenses/by/4.0/

\begin{abstract}
Objective: The purpose of this study was to observe the factors related to T4 patients who underwent surgery for colorectal cancer (CRC) with peritoneal carcinomatosis. Methods: $154 \mathrm{~T} 4$ colorectal cancer patients who underwent surgery in the first Affiliated Hospital of Sun Yat-sen University were included in the study between August, 1994 and December, 2005. Some clinical variables were selected and statistically correlated with prognosis. Results: The overall survival time was 91.7 months at the end of December of 2010 or death. The complete cytoreduction had significant survival benefit than the palliative surgery group. The age, location, histological grade, complete cytoreduction and liver metastasis were associated with overall survival time (OS) according to the univariate analysis $(\mathrm{P}<0.05)$. In addition, Cox multivariate analysis showed that the complete cytoreduction (CCR) and liver metastasis were independent factor influencing survival. Conclusion: Compared with palliative surgery, the incomplete cytoreduction fails to improve patient prognosis. Patients performed completed cytoreduction have a relative good prognosis.
\end{abstract}

\section{Keywords}

Colorectal Cancer, Peritoneal Carcinomatosis, Surgery, Prognosis

*These authors have contributed equally to this work and should be jointly regarded the first. 


\section{Background}

Colorectal cancer (CRC) is one of the most common malignant tumors in the world, with high mortality [1]. There are about $10 \%-20 \%$ of patients with CRC with locally advanced disease, such as $\mathrm{T} 4 \mathrm{a}$ and $\mathrm{T} 4 \mathrm{~b}$ [2]. Surgical resection is one of the main treatment methods for T4 CRC patients. The survival of patients has improved because of the multiple treatment strategy including perioperative chemotherapy and surgery. The mean overall survival of T4 CRC is $12-15$ months [3]. This can be partly explained that the tumor of T4 CRC is likely to spread in the peritoneal cavity, which is named as peritoneal carcinomatosis (PC). The occurrence of PC after operation varied from $4 \%$ to $19 \%$ [4]. The palliative chemotherapy plus hyperthermic intraperitoneal chemotherapy (HIPEC) were used to treat the PC in CRC. The 5-year survival rate is about 40\% [5].

There is increasing evidence reporting that PC was risk factor for the survival or tumor recurrence in gastrointestinal neoplasms in including gastric, esophageal and liver cancers [6] [7] [8]. However, to our knowledge, the effect of PC with T4 CRC has never been report. Despite some studies performed in CRC patients, lots of studies have some limitations including heterogeneous populations, with a relatively small sample of T4 CRC patients.

The background knowledge was the impetus for this study which aimed to analyze the clinical data and survival of T4 CRC patients with PC, and to explore the influence of different surgical methods and clinicopathological factors on the prognosis of patients with CRC.

\section{Materials and Methods}

\section{General information}

A total of 154 data of T4 CRC patients who underwent surgery were obtained in The First Affiliated Hospital of Sun Yat-sen University between August, 1994 and December, 2005. The number of patients in complete cytoreduction (CCR) group and the incomplete cytoreduction group were 103 and 51, respectively. $\mathrm{Pa}$ tients were divided in two groups: patients who are with and without PC. The two groups were then compared in terms of overall survival time (OS).

All patients and their families gave informed consent to the study and signed informed consent. The study was approved by the Ethics Committee of Sun Yatsen University.

\section{Research indicators}

1) The CCR score was classified as follows: 0 points means no remnant tumor; 1 point means remnant tumor diameter $<0.25 \mathrm{~cm}$; 2 points means remnant tumor diameter was $0.25-2.5 \mathrm{~cm} ; 3$ points means remnant tumor diameter $>2.5$ $\mathrm{cm}$ or presence of unresectable lesions. Surgical methods: complete resection refers to tumor CCR of 0 or 1 point, incomplete resection refers to tumor CCR of 2 or 3 points, palliative surgery refers to no cytoreductive surgery and only neostomy or short-circuit surgery. 2) Peritoneal carcinomatosis index (PCI): The abdominal cavity was divided into 13 regions, each region was rated 0 to 3 points 
according to the size of metastatic cancer, and the sum of the scores of each region was PCI ( 0 - 39 points) which is the most commonly used scoring system for assessing the severity of peritoneal metastases.

\section{Follow-up and review}

The patients were followed up every 3 months for the first year, 6-monthly for the next 2 years and yearly thereafter after surgery. The first review was performed at the hospital one month after the operation. Routine review of chest and abdomen CT, blood routine, liver and kidney function, tumor markers, colonoscopy and other examinations, if necessary, whole body bone scan and PET-CT to see if there is systemic metastasis. The OS is from the date of surgery to the death or follow-up deadline.

\section{Statistics method}

Using spss 23.0 software, Kaplan-Meier method was used to calculate OS, and Log-rank method was used to test; Cox model was used for single factor and multifactor analysis, and $\chi^{2}$ test was used to analyze the effect of different treatment methods on survival rate. $\mathrm{P}<0.05$ was considered statistically significant.

\section{Result}

\section{Patients and tumor characteristics}

The demographic and pathological characteristics of T4 CRC are summarized in Table 1 . The mean age of T4 CRC patients without PC and with PC were 58.18 years (range, 25 - 87 years) and 56.58 years (range, 19 - 87 years), respectively. There are statistically significant differences in $\mathrm{N}$ stage, age and histological grade between two groups.

\section{Survival}

The 10-year survival rates of T4 CRC patients without PC and with PC were $49.0 \%$ and $32.2 \%$ in two group and the median survival was 58.8 months, respectively. Univariate analysis showed that the age, location, histological grade, CCR and liver metastasis were associated with OS $(\mathrm{P}<0.05)$. The gender, $\mathrm{N}$ stage, family history were not associated with $\mathrm{OS}(\mathrm{P}>0.05)$. Cox multivariate analysis showed that CCR and liver metastasis were independent factor influencing patient survival. Compared with liver metastasis-negative patients, the risk of death in patients with liver metastasis was increased by 3.450 times $(95 \% \mathrm{Cl}$ : 1.443 - 5.712, $\mathrm{P}=0.017)$. See Table 2.

\section{Comparison of incomplete resection and palliative surgery case}

The comparison of patients in both group was shown in Table 3. There are statistically significant differences in liver metastasis between two groups. There were no significant differences in the remaining indicators in Table 3. The complication rate of incomplete incision group was $21.3 \%$ of patients, respectively. The mortality rate at 30 days after surgery was $6.7 \%$. In the palliative surgery group, the complication rate and the 30 -day mortality rate were 0 of the patients. 
The survival curves of patients with different surgical procedures was shown in Figure 1. The mean survival time was 102.9 months in the CCR group, and survival rate was $49.0 \%$ in 10 nd years, and the patients in CCR group was $6 \%$. The mean survival time of palliative surgery group was 19.7 months, respectively. The above three groups of differences were statistically significant $(\mathrm{P}<0.001)$. A pairwise comparison found that patients in the CCR group had a significant survival benefit compared with the palliative surgery group $(\mathrm{P}<0.05)$, while patients in the incomplete resection group had no survival benefit $(\mathrm{P}=0.217)$.

Table 1. Characteristics on demographics, operations, and pathology in 154 patients of T4 colorectal cancer with PC.

\begin{tabular}{|c|c|c|c|c|}
\hline \multirow{2}{*}{ Characteristics } & \multirow{2}{*}{ Cases } & \multicolumn{2}{|c|}{$\mathrm{PC}$} & \multirow{2}{*}{$\mathrm{P}$} \\
\hline & & No & Yes & \\
\hline Gender & & & & 0.800 \\
\hline Female & 61 & 47 & 14 & \\
\hline Male & 93 & 70 & 23 & \\
\hline Age $\left(\right.$ years) ${ }^{\mathrm{a}}$ & & & & 0.006 \\
\hline$\geq 65$ & 56 & 39 & 17 & \\
\hline$<65$ & 98 & 86 & 12 & \\
\hline Location & & & & 0.353 \\
\hline Colon & 73 & 53 & 20 & \\
\hline Rectum & 81 & 64 & 17 & \\
\hline CCR & & & & 0.089 \\
\hline No & 103 & 85 & 18 & \\
\hline Yes & 51 & 36 & 15 & \\
\hline $\mathrm{N}$ stage & & & & 0.000 \\
\hline No & 74 & 56 & 18 & \\
\hline $\mathrm{N} 1-\mathrm{N} 2$ & 80 & 31 & 49 & \\
\hline Histological grade & & & & 0.006 \\
\hline Well+ Moderately & 101 & 86 & 15 & \\
\hline Poorly & 53 & 35 & 18 & \\
\hline Family history & & & & 0.162 \\
\hline No & 141 & 119 & 22 & \\
\hline Yes & 13 & 9 & 4 & \\
\hline Liver metastasis & & & & 0.239 \\
\hline No & 147 & 128 & 19 & \\
\hline Yes & 7 & 5 & 2 & \\
\hline
\end{tabular}

a Patients were divided according to the median values of age. 
Table 2. The univariate and multivariate analyses of individual parameters associated with OS.

\begin{tabular}{|c|c|c|c|c|c|}
\hline \multirow{2}{*}{ Variable } & \multicolumn{2}{|c|}{ Univariate analysis } & \multicolumn{2}{|c|}{ Multivariate analysis } & \multirow{2}{*}{$\mathrm{P}$} \\
\hline & 10 year-OS & $P$ value & HR & CL (95\%) & \\
\hline Gender & & 0.061 & & & \\
\hline Female & 35.7 & & & & \\
\hline Male & 46.2 & & & & \\
\hline Age $(y)$ & & 0.034 & & & \\
\hline$\geq 65$ & 29.0 & & & & \\
\hline$<65$ & 50.8 & & & & \\
\hline Location & & 0.033 & & & \\
\hline Colon & 51.8 & & & & \\
\hline Rectum & 35.4 & & & & \\
\hline Histological grade & & 0.000 & & & \\
\hline Well+ Moderately & 47.5 & & & & \\
\hline Poorly & 0.06 & & & & \\
\hline $\mathrm{N}$ stage & & 0.362 & & & \\
\hline No & 50.4 & & & & \\
\hline $\mathrm{N} 1-\mathrm{N} 2$ & 33.1 & & & & \\
\hline CCR & & 0.021 & & & 0.031 \\
\hline No & 10.4 & & 1 & & \\
\hline Yes & 42.6 & & 0.65 & $0.45-2.41$ & \\
\hline Family history & & 0.445 & & & \\
\hline No & 43.9 & & & & \\
\hline Yes & 30.0 & & & & \\
\hline Liver metastasis & & 0.000 & & & 0.017 \\
\hline No & 48.0 & & 1 & & \\
\hline Yes & 0.06 & & 3.450 & $1.443-5.714$ & \\
\hline
\end{tabular}

Table 3. Comparison of incomplete resection and palliative surgery case.

\begin{tabular}{ccccc}
\hline Characteristics & Cases & Incomplete resection & Palliative surgery & $\mathrm{P}$ \\
\hline Gender & & & 10 & 0.688 \\
Female & 21 & 11 & 16 & \\
Male & 30 & 14 & & 0.331 \\
Age (years) & & & 13 & \\
$\geq 65$ & 25 & 12 & 10 & \\
$<65$ & 26 & 16 & & 0.971 \\
\hline
\end{tabular}




\section{Continued}

\begin{tabular}{ccccc}
\hline Colon & 29 & 17 & 12 & \\
Rectum & 22 & 13 & 9 & 0.098 \\
N stage & & & 6 & \\
N0 & 18 & 12 & 19 & 0.761 \\
N1-N2 & 33 & 14 & & \\
Histological grade & & & 10 & 0.017 \\
Well+ Moderately & 21 & 11 & 13 & \\
Poorly & 30 & 17 & & \\
Liver metastasis & & 3 & 25 & \\
No & 28 & 9 & & \\
Yes & 23 & 34 & \\
\hline
\end{tabular}

apatients were divided according to the median values of age.

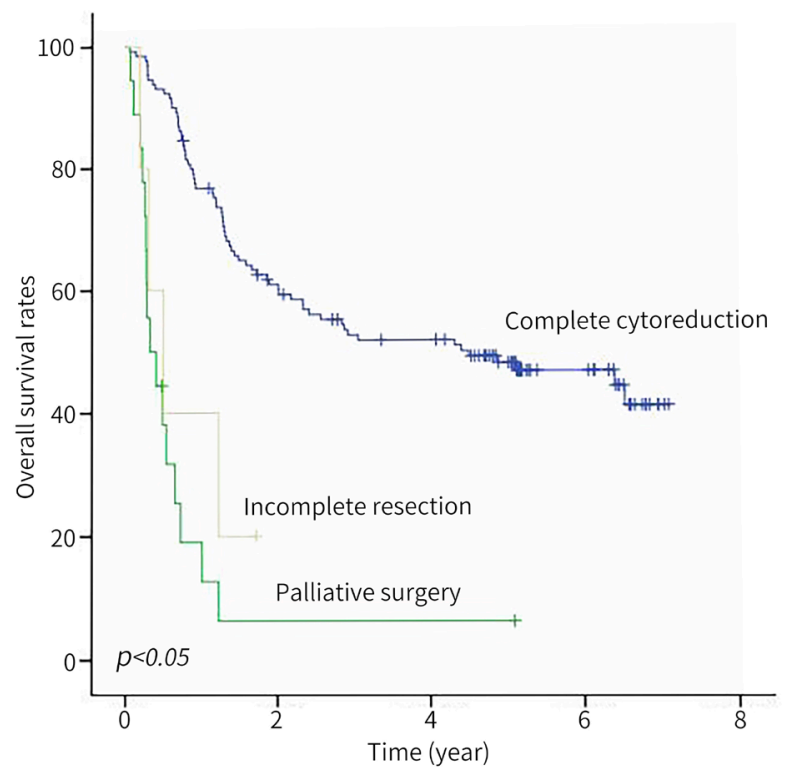

Figure 1. Survival curve for T4 CRC patients undergone different surgical procedures.

\section{Discussion}

CRC has risen to the third most common malignant tumor in China. In view of the fact that domestic screening for early CRC has not been promoted and the population was aging, PC of CRC was becoming an important issue in clinical practice. According to reports in the literature [4], the ratio of T4 CRC developing PC is $17 \%$, which is similar to our study. The 5 -year survival rate of patients with T4 stage CRC is $30 \%$ [9]. The number of positive lymph nodes was associated with PC in T4 patients [10]. In our studies, we specially chose the patients with $\mathrm{T} 4$ tumors because the occurrence of $\mathrm{PC}$ would be very low in patients with lower T-stage patient. 
This study found CCR and whether or not combined with extraperitoneal dissemination were independent factors influencing the prognosis of patients with peritoneal dissemination of T4 CRC patients, consistent with previous studies. The results of this study also showed that patients with complete resection had a median survival time of 102.9 months, significantly longer than incomplete resection and palliative surgery $(\mathrm{P}<0.05)$. The median survival time of patients with combined extraperitoneal metastasis was significantly shorter than that of simple peritoneal metastasis, which is similar to previous study, in which the 3-year overall survival rate $(40.0 \%$ vs. $66.0 \%, \mathrm{P}=0.040)$ in patients with CRC who had both peritoneal metastasis and liver metastases were shorter than those with simple peritoneal metastasis [11]. In addition, there is no survival benefit between the incomplete resection and palliative surgery, the complications of former group and postoperative 30 days mortality were higher. Some study also found that patients with incomplete resection had a median survival of 5.0 months, whereas systemic chemotherapy with or without palliative surgery had a median survival of 12.6 months. The former did not bring survival benefits [12].

Currently, the treatment of primary cancer of stage IV CRC with unresectable metastases and its impact on prognosis remains controversial. Some scholars who support primary cancer resection believe that: 1) Primary cancer resection can reduce complications, such as intestinal obstruction, intestinal perforation, and intestinal bleeding, thus avoiding emergency surgery [13]. 2) Reducing tumor burden may increase the efficacy of chemotherapy. 3) Primary cancer may cause discomfort such as pain that was difficult to relieve, and primary cancer resection can improve the quality of life of patients. However, the others who do not recommend simple primary cancer resection suggest that: 1) The incidence of complications of resection was high, and the patient recovers slowly, resulting in the patient not receiving the appropriate dose of chemotherapy in time [14]. 2) Although several studies have confirmed that simple primary cancer resection can bring survival benefits, these studies were retrospective studies, and there may be patient selective shift [15].

The author believes the PC of CRC patients who were eligible for cytoreductive surgery should meet the following requirements: 1) The general condition of patients was good and can tolerate surgery. 2) PCI $<20$, it was expected that complete resection can be achieved. 3) There was no unresectable extraperitoneal metastasis (such as liver, lung or retroperitoneal lymph node metastasis). For patients with peritoneal dissemination of CRC who can only achieve CCR > 2 point, the purpose of surgery was to treat tumor-related complications and improve the quality of life of patients. Surgery methods with small trauma, short operation time, and low bleeding should be selected as much as possible (such as simple stoma, short circuit surgery, etc.).

Our study has several limitations. One the main limitation includes the single center design and its retrospective nature which might decrease the ability to generalize the results. Second, laparoscopic-assisted resection was not used during the study period, which had gained wide acceptance. The main strength of 
this study is that we provide unique and comprehensive insight into the association between the PC with T4 CRC patients and short- and long-term outcomes.

\section{Conclusion}

To sum up, this study showed that CCR and liver metastasis were independent factor influencing T4 CRC patient survival with PC. Patients performed CCR have a relative good prognosis. The incomplete cytoreduction fails to improve the prognosis of patient, compared with palliative surgery. Individualized treatment of patients can prolong their survival time and improve their quality of life.

\section{Acknowledgements}

Funding for this trial was generously provided by Sun Yat-sen University.

\section{Funding}

This study was supported by the Guangdong Natural Science Foundation (2014A030310021).

\section{Availability of Data and Materials}

The datasets used and/or analyzed during the current study are available from the corresponding author on reasonable request.

\section{Authors' Contributions}

WC and XPT study design, data collection, data analysis and interpretation, draft of the manuscript, approval of final manuscript, supervision. JWY study design, data collection, data analysis and interpretation, draft of the manuscript, approval of final manuscript, supervision. JLL study design, data collection, data analysis and interpretation, draft of the manuscript, approval of final manuscript, supervision. MJH study design, data collection, data analysis and interpretation, revision of the manuscript, approval of final manuscript. All authors approved the final version of the manuscript.

\section{Ethics Approval and Consent to Participate}

The study was conducted in compliance with all national and international ethical standards for research with humans. All study procedures were approved by the Research Ethics Board of the Six Affiliated Hospital, Sun Yat-sen University and patients gave written informed consent before being enrolled.

\section{Conflicts of Interest}

The authors declare no conflicts of interest regarding the publication of this paper.

\section{References}

[1] Brenner, H., Kloor, M. and Pox, C.P. (2014) Colorectal Cancer. Lancet, 383, 1490 - 
1502. https://doi.org/10.1016/S0140-6736(13)61649-9

[2] Gebhardt, C., Meyer, W., Ruckriegel, S. and Meier, U. (1999) Multivisceral Resection of Advanced Colorectal Carcinoma. Langenbeck's Archives of Surgery, 384, 194-199. https://doi.org/10.1007/s004230050191

[3] Jayne, D.G., Fook, S., Loi, C. and Seow-Choen, F. (2002) Peritoneal Carcinomatosis from Colorectal Cancer. British Journal of Surgery, 89, 1545-1550.

https://doi.org/10.1046/j.1365-2168.2002.02274.X

[4] Santvoort, H.C.V., Braam, H.J., Spekreijse, K.R., Koning, N.R., de Bruin, P.C., de Vries Reilingh, T.S., et al. (2014) Peritoneal Carcinomatosis in T4 Colorectal Cancer: Occurrence and Risk Factors. Annals of Surgical Oncology, 21, 1686-1691. https://doi.org/10.1245/s10434-013-3461-0

[5] Koppe, M.J., Boerman, O.C., Oyen, W.J. and Bleichrodt, R.P. (2006) Peritoneal Carcinomatosis of Colorectal Origin: Incidence and Current Treatment Strategies. Annals of Surgery, 243, 212-222. https://doi.org/10.1097/01.sla.0000197702.46394.16

[6] Takeshita, K., Liu, Y., Ishibashi, H. and Yonemura, Y. (2017) Laparoscopic Hyperthermic Intraperitoneal Chemotherapy for Peritoneal Carcinomatosis from Gastric Cancer: Its Beneficial Effects on Reduction and Exact Evaluation of the Peritoneal Cancer Index. American Surgeon, 83, 1315-1320. https://doi.org/10.1177/000313481708301138

[7] Lukas, R.V., Mata-Machado, N.A., Nicholas, M.K., Salgia, R., Antic, T. and Villaflor, V.M. (2016) Leptomeningeal Carcinomatosis in Esophageal Cancer: A Case Series and Systematic Review of the Literature. Diseases of the Esophagus, 28, 772781. https://doi.org/10.1111/dote.12276

[8] Delhorme, J.B., Dupontkazma, L., Addeo, P., Lefebvre, F., Triki, E., Romain, B., et al. (2016) Peritoneal Carcinomatosis with Synchronous Liver Metastases from Colorectal Cancer: Who Will Benefit from Complete Cytoreductive Surgery? International Journal of Surgery, 25, 98-105. https://doi.org/10.1016/j.ijsu.2015.11.025

[9] Gu, F.M., Chi, F.L., Dai, C.F., Chen, B. and Li, H.W. (2013) Surgical Outcomes of 43 Cases with Adenoid Cystic Carcinoma of the External Auditory Canal. American Journal of Otolaryngology, 34, 394-398. https://doi.org/10.1016/j.amjoto.2013.01.018

[10] Kelder, W., Inberg, B., Schaapveld, M., Karrenbeld, A., Grond, J., Wiggers, T. and Plukker, J.T. (2009) Impact of the Number of Histologically Examined Lymph Nodes on Prognosis in Colon Cancer: A Population-Based Study in the Netherlands. Diseases of the Colon \& Rectum, 52, 260-267. https://doi.org/10.1007/DCR.0b013e3181979164

[11] Maggiori, L., Goéré, D., Viana, B., Tzanis, D., Dumont, F., Honoré, C., et al. (2013) Should Patients with Peritoneal Carcinomatosis of Colorectal Origin with Synchronous Liver Metastases Be Treated with a Curative Intent? A Case-Control Study. Annals of Surgery, 258, 116-121. https://doi.org/10.1097/SLA.0b013e3182778089

[12] Verwaal, V.J., Ruth, S.V., de Bree, E., van Slooten, G.W., van Tinteren, H., et al. (2003) Randomized Trial of Cytoreduction and Hyperthermic Intraperitoneal Chemotherapy versus Systemic Chemotherapy and Palliative Surgery in Patients With Peritoneal Carcinomatosis of Colorectal Cancer. Journal of Clinical Oncology, 21, 3737-3743. https://doi.org/10.1200/JCO.2003.04.187

[13] Gulack, B.C., Nussbaum, D.P., Keenan, J.E., Ganapathi, A.M., Sun, Z.F., Worni, M., et al. (2016) Surgical Resection of the Primary Tumor in Stage IV Colorectal Cancer without Metastasectomy is Associated with Improved Overall Survival Compared to 
Chemotherapy/Radiation Therapy Alone. Diseases of the Colon \& Rectum, 59, 299 305. https://doi.org/10.1097/DCR.0000000000000546

[14] Yun, J.A., Huh, J.W., Park, Y.A., Cho, Y.B., Yun, S.H., Kim, H.C., et al. (2014) The Role of Palliative Resection for Asymptomatic Primary Tumor in Patients with Unresectable Stage IV Colorectal Cancer. Diseases of the Colon \& Rectum, 57, 10491058. https://doi.org/10.1097/DCR.0000000000000193

[15] Bajwa, A., Blunt, N., Vyas, S., Suliman, I., Bridgewater, J., Hochhauser, D., et al. (2009) Primary Tumour Resection and Survival in the Palliative Management of Metastatic Colorectal Cancer. European Journal of Surgical Oncology, 35, 164-167. https://doi.org/10.1016/j.ejso.2008.06.005

\section{Abbreviations}

CRC: Colorectal cancer;

PC: Peritoneal carcinomatosis:

CCR: Complete cytoreduction;

OS: Overall survival;

HIPEC: Hyperthermic intraperitoneal chemotherapy. 